\title{
KARBON TERSIMPAN PADA TEGAKAN BENIH TERIDENTIFIKASI "PAMBELUM" DI KOTA PALANGKA RAYA
}

\author{
Nanang Hanafi ${ }^{1)}$ \\ ${ }^{1}$ Program Studi Kehutanan Fapertahut UM Palangkaraya
}

\begin{abstract}
ABSTRAK
Penelitian ini dilakukan pada plot pengamatan tunggal berukuran $20 \mathrm{~m}$ x $100 \mathrm{~m}$ pada Tegakan Benih Tersertifikasi (TBT) "Pambelum" di Kota Palangka Raya untuk mengetahui cadangan karbon pada lima sumber karbon. Metode yang digunakan dalam penelitian ini adalah metode destruktif/perusakan untuk mengetahui besaran cadangan karbon pada serasah, dan tumbuhan bawah yang ada dalam plot pengamatan, non destruktif/tanpa perusakan untuk mengukur cadangan karbon pada biomassa pohon, nekromassa berkayu, dan akar. Total karbon tersimpan pada TBT Pambelum sebesar 196,695 ton/ha, dimana biomassa pohon menyumbang karbon sebesar 62,67 \% (123,264 ton/ha); perakaran menyumbang karbon sebesar 23,19\% (45,608 ton/ha); simpanan karbon pada tanah sebesar 12,34\% (24,281 ton/ha); serasah sebesar $1,34 \%$ (2,736 ton/ha); tumbuhan bawah sebesar $0,40 \%(0,785$ ton/ha); dan nekromassa berkayu sebesar $0,01 \%$ (0,020 ton/ha).
\end{abstract}

\section{Kata Kunci : karbon tersimpan, TBT Pambelum}

\section{ABSTRACT}

This study was carried out on a single observation plot measuring $20 \mathrm{~m} \times 100 \mathrm{~m}$ in the Tegakan Benih Tersertifikasi (TBT) "Pambelum in Palangka Raya City to determine of carbon stocks in five carbon sources. The method used in this study is destructive methods to determine the amount of carbon stocks in litter, and understorey, non-destructive to measure carbon stocks in tree biomass, woody necromass, and roots. Total carbon stored in TBT Pambelum is 196.695 tons / ha, where tree biomass contributes carbon at 62.67\% (123.264 tons / ha); rooting contributes carbon at $23.19 \%$ (45.608 tons/ha); carbon deposits on land at $12.34 \%$ (24,281 tons/ha); litter of $1.34 \%$ (2.736 tons/ha); understorey of $0.40 \%(0.785$ tons/ha); and woody necromass of $0.01 \%$ (0.020 tons/ha).

\section{Keywords : Carbon stock, TBT Pambelum}

\section{PENDAHULUAN}

Perubahan iklim akibat pemanasan global disebabkan oleh peningkatan konsentrasi gas rumah kaca (GRK), terutama karbondioksida $\left(\mathrm{CO}_{2}\right)$ dan metana $\left(\mathrm{CH}_{4}\right)$. Penyebab peningkatan GRK diantaranya adalah akibat peningkatan pembangunan dan industri berbahan bakar fosil (migas) serta alih fungsi lahan dan hutan. Salah satu sumber emisi GRK di Indonesia adalah sektor kehutanan. Emisi dari sektor kehutanan pada tahun 2009 sebesar $48 \%$ dari seluruh emisi GRK di Indonesia yang disebabkan oleh kegiatan penggunaan lahan, alih fungsi hutan dan lahan, deforestrasi, degradasi dan 
pembakaran (KLH, 2009). Salah satu cara untuk mengendalikan perubahan iklim adalah dengan mengurangi emisi gas rumah kaca $\left(\mathrm{CO}_{2}, \mathrm{CH}_{4}, \mathrm{~N}_{2} \mathrm{O}\right)$ yaitu dengan mempertahankan keutuhan hutan alami dan meningkatkan kerapatan populasi pepohonan di luar hutan.

Dalam kaitannya dengan perubahan iklim, hutan memainkan peranan yang penting, sebagai sumber emisi dan sumber serapan gas rumah kaca. Namun sampai saat ini di Indonesia, sektor kehutanan masih merupakan sumber emisi gas rumah kaca yang cukup besar. Meskipun di tingkat dunia kontribusi sektor perubahan lahan dan kehutanan hanya sekitar 18\%, akan tetapi di tingkat nasional adalah yang terbesar atau 48\% (KLH, 2009). Untuk itu Pemerintah telah menetapkan target penurunan emisi sebesar $26 \%$ tahun 2020 (G 20).

Penyimpanan karbon (carbon pool) didarat adalah biomasa tanaman (tanaman hidup), tanaman yang mati (nekromasa) dan tanah. (IPCC, 2006). Cadangan karbon (carbonstock) yang terdapat di lahan hutan alami di seluruh dunia berjumlah sekitar1.146 Gt (giga ton). Cadangan karbon di hutan alami di Asia bagian tropis relatif lebih tinggi dari pada di daerah sub-tropis, dengan rata-rata sekitar 41-54 Gt C di dalam tanaman dan sekitar 43 Gt di dalam tanah atau rata-rata sekitar 132-174 t/ha di dalam biomasa tanaman dan 139 t/ha di dalam tanah (Dixon et al., 1994 dalam Agus F, et al., 2011). Konsep pengendalian perubahan iklim internasional melalui skema REDD+ yaitu Reduksi Emisi akibat Deforestasi dan Degradasi Hutan Plus, diperlukan upaya konservasi dan pengelolaan kelestarian hutan serta peningkatan cadangan karbon hutan.

Tegakan Benih Teridentifikasi merupakan salah satu upaya melestarikan sumber daya genetik dengan jalan menyediakan benih yang bermutu dari jenis-jenis unggulan suatu daerah. TBT Pambelum berada di Jl. Tjilik Riwut Km 9 Kelurahan Bukit Tunggal Kecamatan Jekan Raya Palangka Raya, dengan luas areal sebesar 3,60 ha ditetapkan sebagai sumber benih dengan No. sertifikat 187/BPTH.KAL-2/STFK/2013 tanggal sertifikat 02 April 2013 dengan jumlah pohon plus sebanyak 2600 pohon dengan jenis lokal yang ditanam jelutung (Dyera polyphylla). Tujuan dari penelitian ini adalah untuk mengetahui potensi cadangan karbon di TBT Pambelum. Hasil akhir dari penelitian diharapkan memberikan gambaran tentang besaran karbon tersimpan di TBT Pambelum. 


\section{METODE PENELITIAN}

Penelitian ini dilaksanakan selama \pm 6 bulan, lokasi pengamatan dan pengambilan sampel dilakukan di TBT Pambelum Jl. Tjilik Riwut Km 9 Kelurahan Bukit Tunggal Kecamatan Jekan Raya Palangka Raya. Analisis data untuk tanah dilakukan di Laboratorium Tanah di Fakultas Pertanian Universitas Lambung Mangkurat Banjarbaru, analisis data serasah dan tumbuhan bawah dilakukan di Laboratorium Fapertahut UM Palangkaraya.

Alat yang digunakan : GPS, phi band, ring sampel, alat pengukur berat (timbangan digital) dengan skala gram; meteran dan tali untuk membuat plot; kompas; gunting stek, oven, tally sheet, kantong/wadah contoh dan kamera digital.

Untuk menaksir biomasa pohon di hutan daerah tropis, direkomendasikan untuk menggunakan persamaan yang dikembangkan oleh Chave, et al (2005) dalam Hairiah K., et al 2011; dengan curah hujan antara 1500-4000 mm/tahun yaitu :

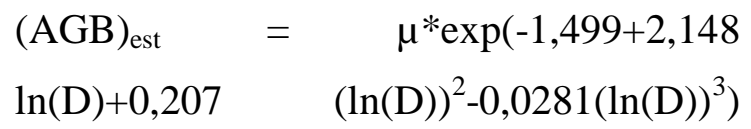
dengan data yang tersedia diameter pohon. Pengukuran biomasa di bawah permukaan tanah dihitung menggunakan rumus sebagai berikut: $\mathrm{Bbp}=\mathrm{NAP} \times$ Bap; dimana Bbp adalah biomasa di bawah permukaan tanah, $(\mathrm{kg})$; NAP adalah nilai nisbah akar pucuk; Bap adalah nilai biomasa atas permukaan (kg); Angka default nisbah pucuk akar (SNI: 7724) untuk hujan tropis adalah 0,37. Kandungan karbon tumbuhan bawah dan serasah per plot dihitung dengan rumus : $\mathrm{C} / \mathrm{plot}=\mathrm{BK}$ x fraksi C (0,46). Untuk nekromassa berkayu, $\mathrm{Bpm}=\mathrm{Vpm} \times \mathrm{BJpm}$; dimana Bpm adalah bahan organik pohon mati, (kg); Vpm adalah volume pohon mati, $\left(\mathrm{m}^{3}\right), \mathrm{Vpm}=\frac{1}{4} \pi\left(\frac{\mathrm{dbh}}{100}\right)^{2} \times \mathrm{t} \times \mathrm{f} ;$ dan BJpm adalah berat jenis kayu pohon mati $\left(\mathrm{kg} / \mathrm{m}^{3}\right)$. Penghitungan cadangan karbon dalam plot pengukuran menggunakanpersamaan sebagai berikut: $\mathrm{C} / \mathrm{ha}=(\mathrm{Cbap}+\mathrm{Cbbp}+$ Cserasah $+\mathrm{Ctb}+\mathrm{Cpm}+\mathrm{Ctanah})$.

\section{HASIL PENELITIAN}

Secara geografis, Kota Palangka Raya terletak pada: $113^{0} 30^{\prime}-114^{0} 07^{\prime}$ Bujur Timur dan $1^{0} 35^{\prime}-2^{0} 24$ ' Lintang Selatan. Luas Palangka Raya 2.853,52 $\mathrm{Km}^{2}$ terbagi dalam lima kecamatan dengan Kecamatan Rakumpit sebagai kecamatan terluas dengan 1.101,95 $\mathrm{km}^{2}$. Wilayah administrasi Kota Palangka Raya terdiri atas 5 (lima) wilayah Kecamatan yaitu Kecamatan Pahandut, Sabangau, Jekan Raya, Bukit Batu dan Rakumpit yang terdiri dari 30 Kelurahan. Suhu rata-rata di Kota Palangka Raya selama tahun 2017 
berkisar antara $27,0{ }^{0} \mathrm{C}$ sampai dengan $28,10^{\circ} \mathrm{C}$. Suhu tertinggi terjadi di bulan Mei dan bulan September 2017sebesar $28,10^{\circ} \mathrm{C}$ dan terendah di bulan Juli sebesar 27,0 ${ }^{0} \mathrm{C}$. Hari Hujan tersebar sepanjang tahun dengan total 186 hari hujan selama tahun 2017. (BPS Kota Palangka Raya, 2017).

Pohon hidup merupakan komponen terbesar penyumbang cadangan karbon di daratan. Data pengamatan biomassa pohon dilakukan pada plot pengamatan ukuran 20x100 m, dan ditemukan pohon sebanyak 104 pohon, terdiri dari jelutung sebanyak Tabel 1. Simpanan karbon pada biomassa pohon
94 pohon, kelapa sawit sebanyak 6 pohon, kelapa sebanyak 1 pohon dan ketapang sebanyak 1 pohon. Keberadaan pohon kelapa sawit, kelapa dan ketapang yang ditemukan pada plot pengamatan sengaja ditanam oleh pemilik kebun, dan merupakan pohon pembatas jalan yang berada di tengah-tengah plot pengamatan, selain itu juga terdapat pohon jelutung dengan diameter $10 \mathrm{~cm}$ sampai dengan $<30$ cm yang berada di pinggir jalan masuk. Jumlah pohon jelutung dengan diameter 10-30 cm ditemukan sebanyak 52 pohon, diameter $>30 \mathrm{~cm}$ sebanyak 44 pohon.

\begin{tabular}{|c|c|c|c|c|c|}
\hline \multirow{2}{*}{ Jenis Pohon } & \multicolumn{2}{|c|}{ BK Biomassa Pohon $(\mathrm{Kg})$} & \multirow{2}{*}{$\begin{array}{c}\text { Total BK } \\
\text { Biomassa } \\
\text { Pohon }(k g) \\
\end{array}$} & \multirow{2}{*}{$\begin{array}{c}\text { Total BK } \\
\text { Biomassa Pohon } \\
(\mathrm{kg} / \mathrm{ton}) \\
\end{array}$} & \multirow{2}{*}{$\begin{array}{c}\text { Simpanan } \\
\text { Karbon } \\
\text { (ton/ha) }\end{array}$} \\
\hline & $\varnothing 10-30 \mathrm{~cm}$ & $\varnothing>30 \mathrm{~cm}$ & & & \\
\hline Jelutung & $10,908.43$ & $42,079.89$ & $52,988.32$ & 264.94 & 121.87 \\
\hline $\begin{array}{l}\text { Kelapa } \\
\text { sawit }\end{array}$ & 0 & 453.89 & 453.89 & 2.27 & 1.04 \\
\hline Kelapa & 6.18 & 0 & 6.18 & 0.03 & 0.01 \\
\hline Ketapang & 144.63 & 0 & 144.63 & 0.72 & 0.33 \\
\hline Total & $11,059.23$ & $42,533.79$ & $53,593.02$ & 267.97 & 123.26 \\
\hline
\end{tabular}

Sumber : Hasil analisis data primer, 2018.

Hasil analisis diketahui bahwa meskipun jumlah pohon jelutung yang berdiameter 10-30 cm lebih banyak ditemukan tetapi memberikan sumbangan BK biomassa lebih sedikit dibandingkan pohon berdiameter $>30 \mathrm{~cm}$. Perbedaan berat kering ini dikarenakan diameter pohon yang ditemukan pada plot pengamatan berbeda, sehingga mempengaruhi besarnya berat kering biomassa pohon. Semakin besar diameter pohon yang ditemukan maka akan menyumbang berat kering biomassa semakin besar.

Pohon jelutung ditanam dengan sistem gundukan dengan pengaturan saluran drainase serta pemberian ameliorasi lahan. Hal ini dilakukan karena lahan termasuk dalam gambut pasang 
surut. Pada biomassa tumbuhan bawah

didapatkan data sebagai berikut :

Tabel 2. Simpanan karbon pada biomassa tumbuhan bawah

\begin{tabular}{|c|c|c|c|c|c|}
\hline \multirow{2}{*}{ No. } & \multirow{2}{*}{$\begin{array}{l}\text { Total Berat } \\
\text { Basah (gr) }\end{array}$} & \multirow{2}{*}{$\begin{array}{c}\text { Sub Contoh } \\
\text { Berat Basah (gr) }\end{array}$} & \multirow{2}{*}{$\begin{array}{c}\text { Sub Contoh } \\
\text { BK (gr) }\end{array}$} & \multicolumn{2}{|c|}{ Total Berat Kering } \\
\hline & & & & $\mathrm{Kg} / \mathbf{0 . 2 5} \mathrm{m}^{2}$ & $\mathrm{Kg} / \mathrm{m}^{2}$ \\
\hline 1 & 306 & 130 & 30 & 0.0706 & 0.2825 \\
\hline 2 & 331 & 177 & 35 & 0.0655 & 0.2618 \\
\hline 3 & 196 & & 40 & 0.0400 & 0.1600 \\
\hline 4 & 155 & & 33 & 0.0330 & 0.1320 \\
\hline 5 & 104 & & 23 & 0.0230 & 0.0920 \\
\hline 6 & 81 & & 24 & 0.0240 & 0.0960 \\
\hline \multicolumn{5}{|c|}{ Jumlah Berat Kering } & 1.0243 \\
\hline \multicolumn{5}{|c|}{ Rata-rata BK $\left(\mathrm{kg} / \mathrm{m}^{2}\right)$} & 0.1707 \\
\hline \multicolumn{5}{|c|}{ Berat Kering Tumbuhan Bawah (ton/ha) } & 1.707 \\
\hline
\end{tabular}

Sumber : Hasil analisis data primer, 2018

Kandungan karbon tumbuhan bawah dihitung dengan rumus: Cton/ha $=$ BKtb $\quad x$ fraksi C $(0,46)$; sehingga didapatkan simpanan karbon pada tumbuhan bawah sebesar 0,785 ton/ha.

Pengukuran biomassa bawah permukaan tanah menggunakan data nisbah akar pucuk (SNI 7724-2011) dikali

Tabel 3. Simpanan karbon pada biomassa bawah permukaan tanah

\begin{tabular}{lrrrrr}
\hline $\begin{array}{c}\text { Jenis } \\
\text { Pohon }\end{array}$ & $\begin{array}{c}\text { Total BK } \\
\text { Biomassa } \\
\text { Pohon (kg) }\end{array}$ & $\begin{array}{c}\text { Nisbah } \\
\text { Akar } \\
\text { Pucuk }\end{array}$ & $\begin{array}{c}\text { Total BK Biomassa } \\
\text { Bawah Permukaan } \\
\text { Tanah (kg) }\end{array}$ & $\begin{array}{c}\text { Total BK } \\
\text { Biomassa Bwh } \\
\text { Perm. Tanah } \\
\text { (ton/ha) }\end{array}$ & $\begin{array}{c}\text { Simpanan } \\
\text { Karbon } \\
\text { (ton/ha) }\end{array}$ \\
\hline Jelutung & 52988.317 & 0.37 & 19605.677 & 98.028 & 45.093 \\
Klp sawit & 453.895 & 0.37 & 167.941 & 0.840 & 0.386 \\
Kelapa & 6.181 & 0.37 & 2.287 & 0.011 & 0.005 \\
Ketapang & 144.626 & 0.37 & 53.512 & 0.268 & 0.123 \\
\hline Total & 53593.019 & & 19829.417 & 99.147 & 45.608 \\
\hline
\end{tabular}

Sumber : Hasil analisis data primer, 2018

Nekromassa merupakan komponen penting dari karbon tersimpan pada suatu lahan dan harus diukur pula agar diperoleh estimasi penyimpanan $\mathrm{C}$ yang akurat.

Tabel 4. Simpanan karbon pada nekromassa berkayu

\begin{tabular}{|c|c|c|c|c|}
\hline \multirow{2}{*}{ No. } & \multicolumn{3}{|c|}{ Nekromassa } & \multirow[t]{2}{*}{$\mathbf{K}$} \\
\hline & FK 0,9 & K 0,8 & FK 0,7 & \\
\hline
\end{tabular}




\begin{tabular}{|c|c|c|c|c|c|c|c|}
\hline \multirow{2}{*}{ No. } & \multicolumn{3}{|c|}{ Nekromassa } & \multirow{2}{*}{$\begin{array}{c}\text { Keliling } \\
\text { (cm) }\end{array}$} & \multirow{2}{*}{$\begin{array}{l}\text { Diameter } \\
(\mathbf{c m})\end{array}$} & \multirow{2}{*}{$\begin{array}{c}\text { Tinggi } \\
(\mathbf{m})\end{array}$} & \multirow{2}{*}{$\begin{array}{c}\text { BK Nekromassa } \\
(\mathrm{kg})\end{array}$} \\
\hline & FK 0,9 & FK 0,8 & FK 0,7 & & & & \\
\hline 1 & & & $\sqrt{ }$ & 33 & 10,510 & 0,3 & 0,416 \\
\hline 2 & & & $\sqrt{ }$ & 36 & 11,465 & 0,25 & 0,413 \\
\hline 3 & & & $\sqrt{ }$ & 48 & 15,287 & 0,37 & 1,086 \\
\hline 4 & & & $\sqrt{ }$ & 27 & 8,599 & 0,18 & 0,167 \\
\hline 5 & & & $\sqrt{ }$ & 38 & 12,102 & 0,27 & 0,497 \\
\hline 6 & & & $\sqrt{ }$ & 36 & 11,465 & 0,15 & 0,248 \\
\hline 7 & & & $\sqrt{ }$ & 48 & 15,287 & 0,36 & 1,057 \\
\hline 8 & & & $\sqrt{ }$ & 64 & 20,382 & 0,4 & 2,087 \\
\hline 9 & & & $\sqrt{ }$ & 24 & 7,643 & 0,74 & 0,543 \\
\hline 10 & & & $\sqrt{ }$ & 26 & 8,280 & 0,64 & 0,551 \\
\hline 11 & & & $\sqrt{ }$ & 32 & 10,191 & 0,84 & 1,096 \\
\hline 12 & & & $\sqrt{ }$ & 18 & 5,732 & 0,95 & 0,392 \\
\hline 13 & & & $\sqrt{ }$ & 15 & 4,777 & 1,25 & 0,358 \\
\hline \multicolumn{7}{|c|}{ Jumlah Nekromassa Berkayu (kg) } & 8,910 \\
\hline \multicolumn{7}{|c|}{ Jumlah Nekromassa Berkayu $\left(\mathrm{kg} / \mathrm{m}^{2}\right)$} & 0,004 \\
\hline \multicolumn{7}{|c|}{ Jumlah Nekromassa Berkayu (ton/ha) } & 0,045 \\
\hline
\end{tabular}

Sumber : Hasil analisis data primer, 2018

Hasil analisis menunjukkan bahwa jumlah nekromassa berkayu yang dapat ditemukan di plot pengamatan ukuran 20x100 m sebanyak 13 batang. Nekromassa yang ditemukan sudah mengalami dekomposisi, dan hancur ketika dilakukan pengukuran keliling dan panjang nekromassa, sehingga tidak dapat dilakukan pengukuran nekromassa. Secara tidak langsung keberadaan nekromassa menahan $\mathrm{C}$ yang dapat ditahan dalam bentuk batang kayu yang lapuk, dibandingkan kehilangan $\mathrm{C}$ dalam bentuk gas di atmosfer. Kandungan karbon nekromassa berkayu dihitung dengan Tabel 5. Simpanan karbon pada nekromassa tak berkayu

\begin{tabular}{|c|c|c|c|c|c|}
\hline \multirow{2}{*}{ No. } & \multirow{2}{*}{$\begin{array}{l}\text { Total Berat } \\
\text { Basah (gr) }\end{array}$} & \multirow{2}{*}{$\begin{array}{c}\text { Sub Contoh } \\
\text { Brt Basah (gr) }\end{array}$} & \multirow{2}{*}{$\begin{array}{c}\text { Sub Contoh } \\
\text { Brt Kering (gr) }\end{array}$} & \multicolumn{2}{|c|}{ Total Berat Kering } \\
\hline & & & & $\mathrm{Kg} / 0.25 \mathrm{~m}^{2}$ & $\mathrm{Kg} / \mathrm{m}^{2}$ \\
\hline
\end{tabular}

rumus: $\mathrm{Cton} / \mathrm{ha}=\mathrm{BK} \times$ fraksi $\mathrm{C}(0,46)$; sehingga didapatkan simpanan karbon pada nekromassa berkayu sebesar 0,020 ton/ha.

Serasah yang jatuh di permukaan tanah dapat melindungi permukaan tanah dari pukulan air hujan dan mengurangi penguapan. Tinggi rendahnya peranan serasah ini ditentukan oleh kualitas bahan organik tersebut. Semakin rendah kualitas bahan, semakin lama bahan tersebut lapuk, sehingga terjadi akumulasi serasah yang cukup tebal pada permukaan tanah hutan (Suprayogo et al., 2003). 


\begin{tabular}{cccccc}
\hline 1 & 391 & 190 & 62 & 0,1276 & 0,5104 \\
2 & 252 & 166 & 53 & 0,0805 & 0,3218 \\
3 & 263 & 162 & 59 & 0,0958 & 0,3831 \\
4 & 508 & 130 & 45 & 0,1758 & 0,7034 \\
5 & 433 & 152 & 67 & 0,1909 & 0,7634 \\
6 & 506 & 162 & 0,2218 & 0,8871 \\
\hline \multicolumn{5}{c}{ Jumlah Berat Kering } & 3,5692 \\
\hline \multicolumn{5}{c}{ Rata-rata BK $\left(\mathrm{kg} / \mathrm{m}^{2}\right)$} & 0,5949 \\
\hline
\end{tabular}

Sumber : Hasil analisis data primer, 2018

Kandungan karbon nekromassa tak berkayu dihitung dengan rumus: Cton/ha $=$ BK x fraksi C $(0,46)$; sehingga didapatkan simpanan karbon pada nekromassa tak berkayu sebesar 2,736 ton/ha.

Tabel 6. Hasil analisis contoh tanah

\begin{tabular}{ccccccc}
\hline \multirow{2}{*}{ No. } & $\begin{array}{c}\text { Kode } \\
\text { Sampel }\end{array}$ & $\mathbf{C - o r g}$ & N-total & $\mathbf{P}_{2} \mathbf{O}_{\mathbf{5}}$ & $\mathbf{K}_{\mathbf{2}} \mathbf{O}$ & \multirow{2}{*}{$\mathbf{p H}\left(\mathbf{H}_{\mathbf{2}} \mathbf{O}\right)$} \\
\cline { 3 - 5 } & & $-----\%$ & ----- & \multicolumn{2}{c}{$---\mathbf{m g} / \mathbf{1 0 0 g}---$} & \\
\hline 1 & K1P1 & 32.04 & 0.48 & 10.53 & 21.73 & 4.35 \\
2 & K2P1 & 25.4 & 0.4 & 10.9 & 13.91 & 4.38 \\
3 & K3P1 & 13.61 & 0.44 & 9.91 & 23.29 & 4.3 \\
4 & K4P1 & 45.58 & 0.36 & 7.83 & 17.52 & 4.29 \\
\hline
\end{tabular}

Sumber : Analisis laboratorium tanah ULM, 2018

Tabel 7. Simpanan karbon tanah di plot pengamatan

\begin{tabular}{cccccc}
\hline No & $\begin{array}{c}\text { Kode } \\
\text { Sampel }\end{array}$ & $\begin{array}{c}\text { \% C- } \\
\text { Org }\end{array}$ & C-Org/ton & $\begin{array}{c}\text { Berat Tanah / } \\
\text { ha (ton) }\end{array}$ & $\begin{array}{c}\text { Kandungan } \\
\text { Karbon / ha }\end{array}$ \\
\hline 1 & K1P1 & 32,04 & 0,032 & 138,23 & 4,43 \\
2 & K2P1 & 25,4 & 0,025 & 126,03 & 3,20 \\
3 & K3P1 & 13,61 & 0,014 & 224,96 & 3,06 \\
4 & K4P1 & 45,58 & 0,046 & 298,14 & 13,59 \\
\hline \multicolumn{5}{c}{ Jumlah (ton/ha) } \\
\hline
\end{tabular}

Sumber : Hasil analisis data primer, 2018

Hasil analisis menunjukkan bahwa kandungan karbon tanah/ha mengalami penurunan pada tingkat kedalaman 0$20 \mathrm{~cm}$, tetapi pada kedalaman $>20 \mathrm{~cm}$ mengalami peningkatan dibandingan kedalaman diatasnya. Hal ini kemungkinan disebabkan karena sistem pengolahan lahan menggunakan sistem gundukan dan pengaturan saluran drainase, dimana tanah galian untuk saluran drainase disebar di 
kiri kanan saluran sehingga menutupi vegetasi diatas permukaan tanah, lambat laut terdekomposisi sehingga menambah kandungan karbon tanah.

Total cadangan karbon diperlukan untuk mengetahui seberapa besar cadangan karbon yang tersimpan dalam carbon pool, hal ini berkaitan dengan pengelolaan lahan Tabel 8. Estimasi Total Cadangan Karbon TBT Pambelum

\begin{tabular}{llcc}
\hline \multicolumn{2}{c}{ Carbon Pool } & $\begin{array}{c}\text { Total BK } \\
\text { (ton/ha) }\end{array}$ & $\begin{array}{c}\text { Total Cadangan C } \\
\text { (ton/ha) }\end{array}$ \\
\hline Biomassa & Pohon & 267,965 & 123,264 \\
& Akar & 99,147 & 45,608 \\
& Tumb. Bawah & 1,707 & 0,785 \\
Nekromassa & Berkayu & 0,045 & 0,020 \\
Tanah & Serasah & 5,949 & 2,736 \\
\hline \multicolumn{2}{c}{} & & 24,281 \\
\hline
\end{tabular}

Sumber : Hasil analisis data primer, 2018

Biomassa tumbuhan bertambah, karena tumbuhan menambat karbon dari udara dan mengubahnya menjadi bahan organik selama fotosintesis; laju fotosintesis merupakan produktivitas primer kotor. Whitmore (1984) dalam MacKinnon et al. (2000) menyatakan di hutan basah/tropis lebih dari tiga perempat zat karbon terdapat di dalam kayu, sedangkan di hutan pohon jarum di daerah iklim sedang, setengah zat karbonnya terdapat di dalam tanah

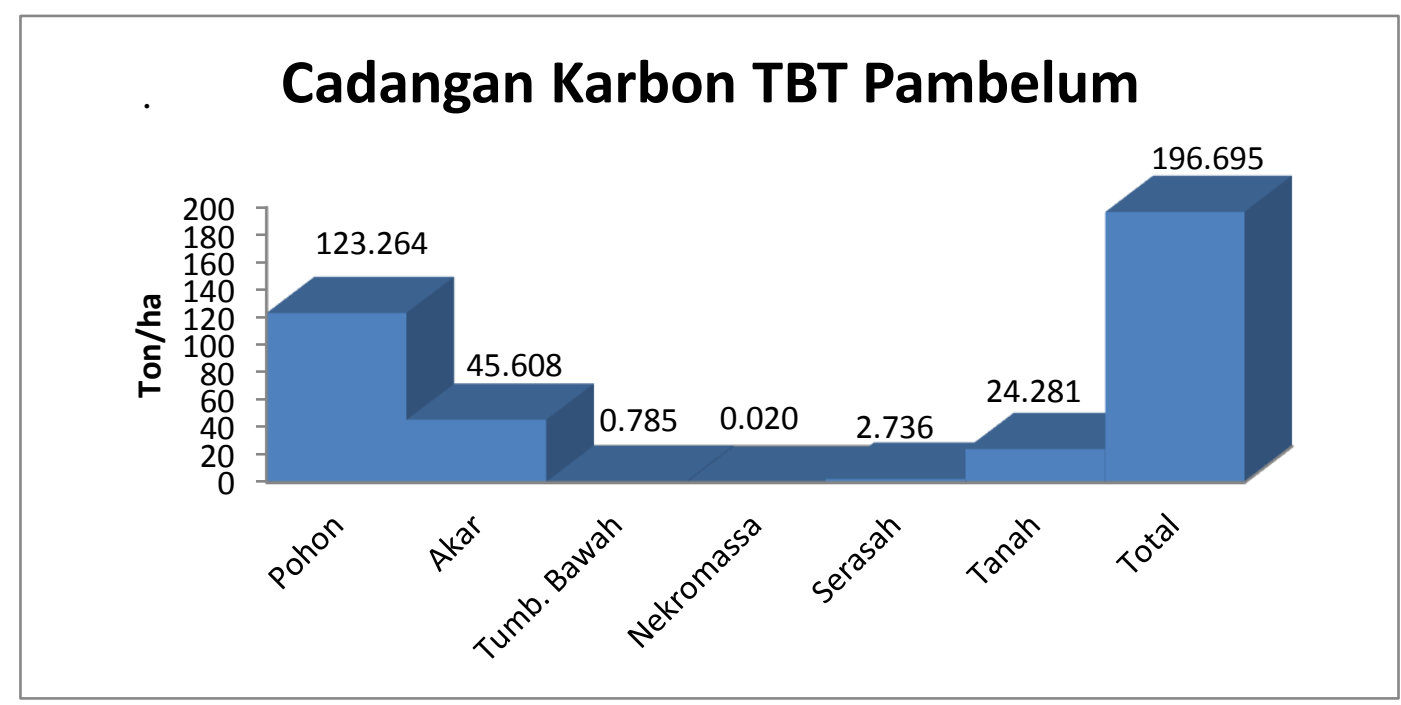

Gambar 1. Cadangan karbon pada TBT Pambelum. 
Gambar diatas menunjukkan bahwa keberadaan pohon menyumbang cadangan karbon sebesar 123,264 ton/ha, perakaran sebesar 45,608 ton/ha, tumbuhan bawah sebesar 0,785 ton/ha, neromassa berkayu sebesar 0,020 ton/ha, serasah sebesar 2,736 ton/ha dan tanah sebesar 24, 281 ton/ha.

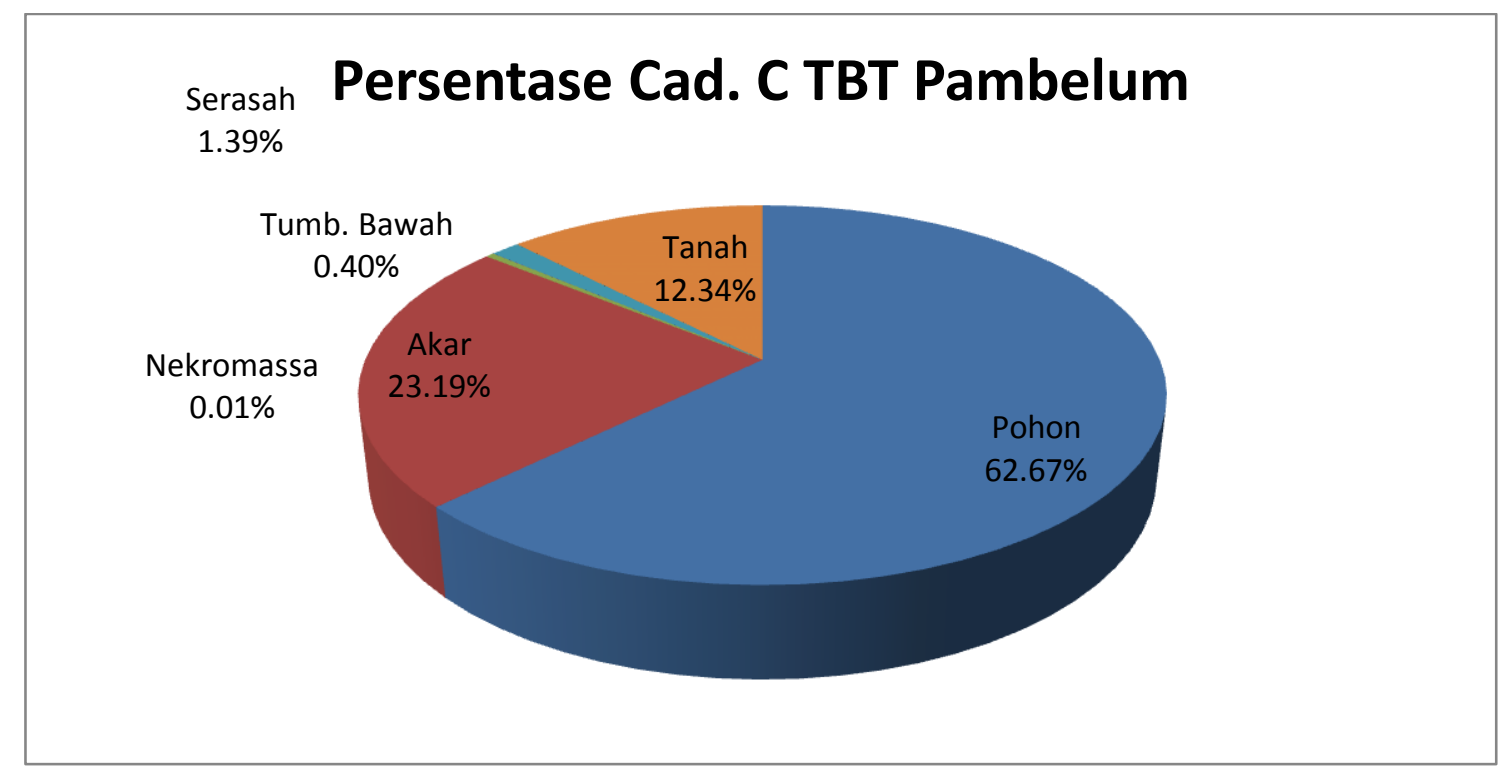

Gambar 2. Persentase cadangan karbon pada TBT Pambelum.

Gambar 2 menunjukkan bahwa keberadaan pohon menyumbang cadangan karbon sebesar $62,67 \%$ dari total cadangan karbon, perakaran menyumbang 23,19\% dari total cadangan karbon, tanah sebesar 12,34\%, serasah sebesar 1,39\%, tumbuhan bawah dan nekromassa $<1 \%$ dari total cadangan karbon TBT Pambelum. TBT Pambelum didominasi oleh pohon jelutung (Dyera polyphylla (Miq.)) sebagai sumber benih di Kota Palangka Raya. Pohon jelutung atau pantung mempunyai akar nafas sehingga memungkinkan pohon tersebut untuk bertahan hidup di lahan yang selalu tergenang. Mempunyai berat jenis sekitar 0,43 .
Keberadaan pohon dengan berat jenis besar akan mempengaruhi cadangan karbon total oleh biomassa pohon. Penelitian yang dilakukan oleh Hanafi N, et al. (2018) pada 3 plot pengamatan di "Kabun" menyatakan bahwa keberadaan biomassa pohon menyumbang cadangan karbon sebesar 81,263 ton/ha; 61,209 ton/ha; dan 65,643 ton/ha. Keberadaan biomassa pohon pada lahan masyarakat terkait dengan fungsi ekonomi yang didapatkan oleh masyarakat. Pada kasus di sistem agroforestri "Kabun" di Kabupaten Katingan, keberadaan biomassa pohon yang didominasi oleh pohon buah-buahan dianggap tidak atau kurang berkontribusi pada pendapatan masyarakat sehingga 
mereka mengganti biomassa penyusun "Kabun" dengan tanaman yang lebih menguntungkan, misalnya pisang dan jengkol.

Tanaman atau pohon berumur panjang yang tumbuh merupakan tempat penimbunan atau penyimpanan $\mathrm{C}(\operatorname{rosot} \mathrm{C}$ $=\mathrm{C}$ sink) yang jauh lebih besar dari pada tanaman semusim. Oleh karena itu, hutan alami dengan keragaman jenis pepohonan berumur panjang dan serasah yang banyak merupakan gudang penyimpan $\mathrm{C}$ tertinggi (baik di atas maupun di dalam tanah). Tumbuhan bawah/semak belukar juga menyimpan cadangan karbon meskipun tidak sebesar tumbuhan berkayu, meskipun demikian keberadaan tumbuhan bawah juga diperhitungkan dalam kegiatan konservasi tanah. Karena keberadaan tumbuhan bawah dan semak belukar dapat melindungi tanah dari kemampuan kinetis air hujan untuk menguraikan partikel tanah, selain itu juga membantu proses masuknya air hujan ke dalam tanah melalui perkarannya.

\section{PENUTUP}

Total cadangan karbon pada TBT Pambelum sebesar 196,695 ton/ha, dimana pohon menyumbang cadangan karbon sebesar 62,67\% atau sebesar 123,264 ton/ha; perakaran menyumbang cadangan karbon sebesar 23,19\% atau sebesar 45,608 ton/ha; tanah me nyumbang cadangan karbon sebesar 12,34\% atau sebesar 24,281 ton/ha; serasah menyumbang cadangan karbon sebesar $1,34 \%$ atau sebesar 2,736 ton/ha; tumbuhan bawah menyumbang sebesar $0,40 \%$ atau sebesar 0,785 ton/ha; dan nekromassa berkayu menyumbang cadangan karbon sebesar $0,01 \%$ atau sebesar 0,020 ton/ha.

\section{DAFTAR PUSTAKA}

Agus F, Hairiah K, Mulyani A. 2011. Pengukuran Cadangan Karbon Tanah Gambut. Petunjuk Praktis. World Agroforestry Centre-ICRAF, SEA Regional Office dan Balai Besar Penelitian dan Pengembangan Sumberdaya Lahan Pertanian (BBSDLP), Bogor, Indonesia. 58 p.

BPS Kota Palangka Raya. 2017. Kota Palangka Raya Dalam Angka. 2017. Badan Pusat Statistik Kota Palangka Raya.

Hanafi N, Afitah I, Jariah J. 2018. Cadangan Karbon pada "Kabun" di Kabupaten Katingan Kalimantan Tengah. Daun : Jurnal Ilmiah Pertanian dan Kehutanan Vol. 5 No. 2 2018. LP2M Universitas Muhammadiyah Palangkaraya.

IPCC. 2006. IPCC Guidelines for National Greenhouse Gas Inventories. IPCC National Greenhouse Gas Inventories Programme. IGES, Japan.

Kementerian Lingkungan Hidup [KLH]. 2009. Indonesia: Second national communication under the united 
nation framework convention on climate change. Kementerian Lingkungan Hidup, Jakarta.

MacKinnon, K; G.M. Hatta; H Halim dan A. Mangalik. 2000. Ekologi Kalimantan. Editor Seri : S.N. Kartikasari. Alih Bahasa : Gembong Tjitrosoepomo, Widyantoro, Agus. Prenhallindo. Jakarta.

SNI 7724. 2011. Pengukuran dan penghitungan cadangan karbon, Pengukuranlapangan untuk penaksiran cadangan karbon hutan (ground based forest carbon accounting). BSN. Jakarta 